\title{
Indícios de Aproximações entre a Educação Ambiental e a Divulgação Científica no Livro Como
} Chegamos até Aqui

Camila Carolina Colpo*, Judite Scherer Wenzel**,

\section{Resumo}

O presente artigo versa acerca da Divulgação Científica e da Educação Ambiental como modo de qualificar a construção do conhecimento científico e promover a formação de leitores com posicionamento crítico em contexto escolar. Para tanto, realizamos uma análise qualitativa documental e o mapeamento de um dos capítulos do livro de Divulgação Científica Como chegamos até aqui, de autoria de Steven Johnson cujo título é Higiene. Com isso foi possível evidenciar as possibilidades didáticas para a sua utilização em sala de aula, com atenção especial para a Educação Ambiental como tema transversal. De modo geral, o livro aborda as inovações e os avanços tecnológicos que constituíram a sociedade atual e que tornaram a vida moderna possível. E, os resultados apresentados possibilitam visualizar que aliar a Divulgação Científica com a Educação Ambiental pode ser um modo de contextualizar questões sócio científicas com um olhar crítico e científico em contexto escolar.

Palavras-chave: Textos de Divulgação Científica, Saúde Pública, Ensino de Ciências.

\section{Considerações Iniciais}

O presente artigo contempla a temática da Divulgação Científica e da Educação Ambiental por meio do uso de Textos de Divulgação Científica (TDC), com atenção para a construção do conhecimento científico e a formação de leitores. Partimos do entendimento de que o conhecimento científico deve ser difundido e divulgado não

\footnotetext{
* Mestranda do Programa de Pós Graduação em Ensino de Ciências (PPGEC), Universidade Federal da Fronteira Sul, Campus Cerro Largo, RS (UFFS/Brasil), Bolsista CAPES/DS. (camilacolpo@hotmail.com)

* Doutora em Educação nas Ciências pela Unijuí-RS. Professora adjunta da Universidade Federal da Fronteira Sul, Campus Cerro Largo. Professora do Programa de Pós Graduação em Ensino de Ciências (PPGEC), (UFFS/Brasil). (juditescherer@uffs.edu.br)
}

Recebido em: 11/02/2020 -27/08/2020.

https://doi.org/10.5335/rbecm.v3i2.10607

http://creativecommons.org/licenses/by-nc-nd/4.0 
somente para a comunidade de cientistas, mas também para a sociedade de modo geral (ZAMBONI, 2001; BUENO, 2010; CUNHA, 2019). E apontamos que uma alternativa para fazer isso em contexto escolar é o uso de TDC que se caracteriza como um modo de Divulgação Científica.

Cunha (2019) indica que a Divulgação Científica compreende processos de interação entre ciência e o público sendo considerada uma ação que tem por objetivo popularizar a Ciência. O termo DC, conforme aponta a autora (2019) está relacionado a outros termos, um mais amplo, que é a difusão científica, que se caracteriza como um processo ou recurso utilizado para comunicar uma informação científica, independente do público (cientistas ou leigos). Já quando a intenção é difundir a ciência entre e/ou para especialistas o termo utilizado é disseminação científica e, quando a intencionalidade é a divulgação do conhecimento científico para leigos e/ou público em geral tem-se o que já indicamos, a divulgação científica, popularização científica ou vulgarização científica.

Bertoldo et al. (2015) indicam que um dos objetivos da Divulgação Científica consiste em tornar conhecido os avanços da Ciência e para isso os meios de divulgação da ciência usam uma linguagem mais clara e próxima da população. Também, conforme aponta Zamboni (2001), para atingir um público mais amplo, tais meios de divulgação fazem uso de múltiplos recursos, técnicas que qualificam a disseminação das informações, permitindo assim, à população uma aproximação com o conhecimento científico que se desenvolveu ao longo do tempo.

Esse movimento de divulgação implica diversos meios como mídias impressas (jornais, livros, revistas), comunicativas (televisão, rádio, internet) e, ainda, espaços não formais de ensino, como museus e centros de ciência, ou seja, as discussões sobre a Divulgação Científica podem se ampliar para várias vertentes (CUNHA, 2019). Porém, considerando a intencionalidade deste trabalho e, outras pesquisas que estamos desenvolvendo ${ }^{1}$ a nossa atenção está voltada para a Divulgação Científica em contexto escolar por meio do uso de textos que divulgam a ciência, chamados de TDC. E, visando potencializar o uso dos mesmos, selecionamos para análise o livro de autoria de Steven Johnson (2015), cujo título é Como chegamos até aqui.

Diversos autores como, Zamboni (2001), Cunha, Giordan (2015) e Cunha (2019) apresentam o TDC como um novo gênero de discurso, ou seja, ao caracterizar o

1 Pesquisa aprovada e financiada pela Chamada Universal CNPQ/2016 com a qual foi criada um Grupo de Estudos de leitura interativa de TDC junto à formação inicial de professores e tem possibilitado outros olhares acerca do uso do TDC. 
discurso do TDC apontam que o mesmo não é uma simples simplificação do discurso científico, mas se caracteriza como "vivo, colorido e envolvente [...] um gênero discursivo que abrange as diferentes manifestações pelas quais a Ciência se dá a conhecer ao público leigo" (ZAMBONI, 2001, p. 85-85). O TDC apresenta estilo e forma que o diferem do discurso científico e, assim, pelas suas especificidades, é caracterizado como gênero discursivo de divulgação científica.

E são essas as especificidades que tem sido apontadas por Ferreira e Queiroz (2012) ao indicar o TDC como um recurso a ser utilizado em sala de aula por apresentar características como a didaticidade (procedimentos didáticos, como explicações e recapitulações), a laicidade (relação com o cotidiano e questões atuais da sociedade) e a cientificidade (conceitos científicos) (FERREIRA; QUEIROZ, 2012).

Ainda, ao considerar o uso do TDC em contexto escolar apontamos que os benefícios do seu uso "passam pelo simples estímulo ao hábito da leitura, podendo alcançar o desenvolvimento da capacidade crítica e uma compreensão mais adequada sobre a ciência por parte do alunado" (FERREIRA; QUEIROZ, 2015, p. 131), e que tal movimento de leitura em sala de aula pode ser potencializado pelo uso de debates, de discussões que visam desenvolver um posicionamento crítico, que contemplem as ideologias e as intencionalidades do TDC. Ou seja, ao oportunizar e instigar tal prática de leitura é possível a formação de cidadãos mais críticos e que saibam se posicionar frente aos avanços científicos e tecnológicos (BERTOLDO et al., 2015).

Aliar o uso do TDC com a necessidade de promover o posicionamento crítico dos estudantes é algo que se mostra emergente nos dias atuais, pois é preciso que o estudante tenha mais do que apenas o acesso à informação mas que ele saiba se posicionar frente à mesma, com uma compreensão mínima de conceitos e assuntos de Ciência e Tecnologia (CUNHA, 2019). Portanto, para que este posicionamento se consolide "é necessário, dentre outras ações, desenvolver competências de ler criticamente, analisar diferentes formas de divulgação, participar de debates e argumentar" (CUNHA, 2019, p. 65). E, nesse âmbito, atualmente um tema em destaque é a Educação Ambiental a qual precisa ser mais dialogada em sala de aula. Apontamos com Reigota (2014) que

a educação ambiental não transmite só o conhecimento científico, mas enfatiza e provoca a necessidade de diálogo entre todo tipo de conhecimento, [...] que permite o cidadão e à cidadã uma melhor atuação e intervenção cotidiana na busca de soluções e alternativas socioambientais (REIGOTA, 2014, p. 54-5). 
Sendo assim indicamos que o uso dos TDC pode ser um aliado no diálogo com a Educação Ambiental que faz uso de questões sócio científicas para traduzir e discutir a linguagem técnico-científica presentes em tais questões, para que essas sejam de compreensão de todos (REIGOTA, 2014). Da mesma forma apontamos que a educação ambiental necessita de conhecimentos específicos, aprofundados, produzidos pelas ciências, artes e culturas. Necessita também construir conhecimentos específicos, provocando o diálogo entre representações sobre um tema e conhecimentos científicos e populares (REIGOTA, 2014, p. 98).

Assim, visando qualificar e ampliar o uso de TDC no contexto escolar e tendo como foco a temática emergente da Educação Ambiental o objetivo dessa pesquisa consistiu em identificar de que forma está contemplada a Educação Ambiental no livro de Divulgação Científica Como chegamos até aqui, de autoria de Steven John-

son. E para tanto, escolhemos para análise um dos capítulos do livro que mais se aproxima com a temática, cujo título é Higiene. Para a análise realizamos o modelo de Mapeamento de TDC proposto por Ferreira e Queiroz (2011). Segue uma descrição dos caminhos metodológicos percorridos.

\section{Caminhos Metodológicos}

A pesquisa desenvolvida é considerada qualitativa do tipo documental (LÜDKE; ANDRÉ, 2001) e consistiu na análise do capítulo quatro do livro de divulgação científica: Como chegamos até aqui, de autoria de Steven Johnson. Tal análise teve a intencionalidade de evidenciar questões sócio científicas principalmente no que se refere à temática ambiental e, em especial, a questões de saúde pública, buscando assim estabelecer relações e aproximações entre a Divulgação Científica e a Educação Ambiental.

Ressaltamos que a escolha do livro esteve condicionada ao fato de que ele faz parte do acervo de livros adquiridos junto ao Grupo de Estudos de leitura interativa de TDC mediante financiamento Chamada Universal CNPQ/2016. O Grupo de Estudos acontece desde 2016, está vinculado à um curso de Química Licenciatura de uma Universidade Federal do Sul do País. Participam do grupo licenciandos, em torno de 10 a 15, quatro professoras formadoras do curso de Química Licenciatura, alunos do Ensino Médio (bolsistas de Iniciação Científica), professores da rede pública de ensino. No Grupo de Estudos são realizados encontros mensais, 
nos quais são desenvolvidos diálogos referentes à livros de TDC previamente lidos pelos participantes.

Os diálogos são realizados a partir de diferentes estratégias de leitura elaboradas e conduzidas pelos integrantes do grupo. A leitura é conduzida por meio de diferentes estratégias de leitura e diálogo sobre o texto (COLPO, 2019) e por meio de um processo interativo são apontados alguns aspectos principais, de forma especial, indicando as possibilidades para o uso em sala de aula. Para auxiliar no estudo dos TDC temos utilizado a proposta de Mapeamento de TDC (FERREIRA; QUEIROZ, 2011). Destacamos que o livro, cuja análise aqui apresentamos, ainda não foi objeto de estudo no grupo, mas outras obras do autor sim, como A Invenção do ar (JOHNSON, 2009) e $O$ mapa fantasma (JOHNSON, 2008). E com isso justificamos a escolha pelo livro, pois já tivemos contato com o estilo e com algumas das temáticas abordadas pelo autor.

O Mapeamento de TDC de acordo com Ferreira e Queiroz (2011) contempla tanto o conteúdo como a forma do texto e possibilita inferir ao texto suas potencialidades didáticas para possível utilização em sala de aula por parte dos professores. No que diz respeito ao conteúdo, as autoras o caracterizam como análise geral, e visa identificar quais os principais conteúdos presentes no TDC. Na análise que realizamos utilizamos um olhar para o Ensino de Ciências, contemplando assim subcategorias: Conceitos de Ciências estruturantes do ensino escolar; Fronteiras, que abarca conteúdos que não se caracterizam como de Ciências, mas que tenham relação com os demais conteúdos abordados no texto e que tenham relação com ele e; Temas Transversais, que são os conteúdos que não pertencem a uma disciplina específica, mas que perpassa várias e tenham relevância social (FERREIRA; QUEIROZ, 2011).

A outra análise é denominada como uma análise específica e consiste em identificar no texto a temática, que indica o tema central abordado; as características da atividade científica, que inclui, a descrição dos métodos e das condições de produção da ciência e; as abordagens e contexto, que permite indicar o contexto social, político e econômico no qual o texto está inserido. Já a forma do texto é contemplada considerando a estrutura do texto, nesta é possível indicar como as informações estão distribuídas; qual a linguagem utilizada, que diz respeito à clareza do texto e o uso de recursos como analogias e metáforas, por exemplo e; os recursos visual e textual utilizados, num indicativo do uso de imagens, quadros ou boxes, o que permite visualizar a distribuição espacial das informações (FERREIRA, QUEIROZ, 2011). 
Antes de apresentarmos o mapeamento elaborado para o capítulo quatro, segue uma descrição mais geral acerca do autor e do livro, tendo como objetivo a apresentação do mesmo a fim de contextualizar a análise que foi realizada.

\section{O livro Como chegamos até aqui}

$\mathrm{O}$ autor Steven Johnson é um renomado escritor de Ciência norte americano e um dos mais destacados conhecedores da história da Ciência e da Tecnologia. É autor de vários livros traduzidos para muitas línguas, elaborou e mantém sites na internet onde divulga questões relacionadas à Ciência e Tecnologia, em especial a evolução da internet ${ }^{2}$ e as evoluções científicas. Também é diretor de séries exibidas por redes como a BBC (British Broadcasting Corporation), por exemplo, como a série How We Got to Now, que deu origem ao livro Como Chegamos até aqui ${ }^{3}$.

O referido livro aborda de forma especial as inovações e os avanços tecnológicos constitutivos do percurso histórico da sociedade atual e que tornaram a vida moderna tal qual a conhecemos possível. O livro está subdividido em seis áreas temáticas, cada qual compreende um capítulo do livro: vidro, frio, som, higiene, tempo e luz.

Considerando a intencionalidade de aproximar o livro das temáticas ambientais, optamos por analisar o capítulo quatro, que tem por título Higiene e que discute de forma mais explícita sobre tal área temática contemplando aspectos relacionados à saúde pública. Em tal capítulo estão retratados principalmente aspectos do saneamento básico. O autor traça uma linha temporal desde as primeiras preocupações com o descarte dos dejetos até as mais atuais e modernas inovações nessa área. Instigados pela forma como o autor aborda tais questões optamos por realizar o Mapeamento deste capítulo e indicar as potencialidades deste para a sala de aula, com atenção para a Educação Ambiental. Segue um detalhamento do mapeamento realizado para esse capítulo.

2 https://stevenberlinjohnson.com/

3 https://zahar.com.br/autor/steven-johnson 


\section{O mapeamento do TDC}

No capítulo quatro, intitulado de Higiene, Johnson (2015, p. 110) retrata a época de 1850 e descreve os estudos realizados por Ellis Chesbrough, cujo objetivo foi "analisar as invisíveis realizações da engenharia europeia". Visando indicar as possibilidades de diálogo entre o capítulo do TDC e a Educação Ambiental, optamos por realizar o Mapeamento do texto, e apontar as possibilidades deste para a sala de aula. O Mapeamento do TDC realizado possibilitou, indicar como a Educação Ambiental está contemplada no texto e também aponta para mais possibilidades de uso do texto em sala de aula. Segue na Figura 1, o Mapeamento do TDC que foi adaptado da proposta de Ferreira e Queiroz (2011).

Figura 1: Mapeamento do TDC Higiene

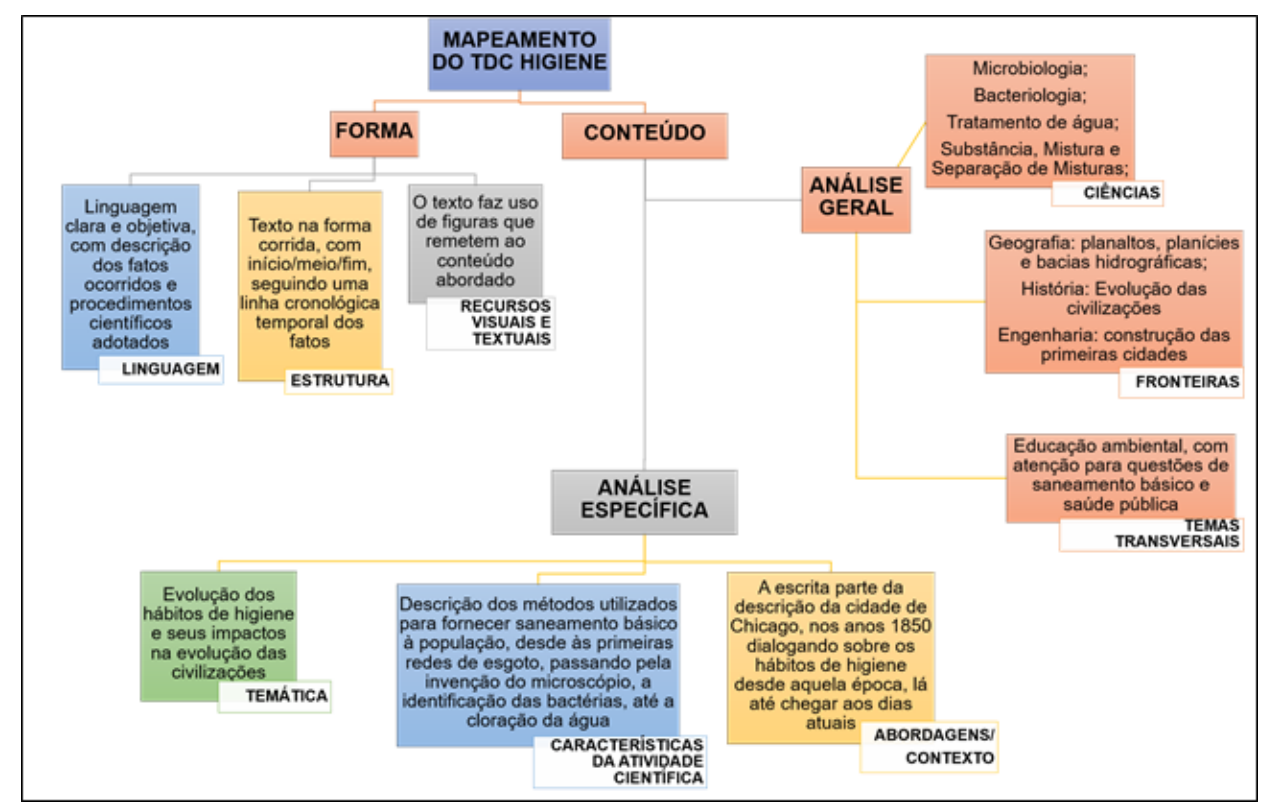

Fonte: as autoras (2020)

O mapeamento realizado possibilita indicar o TDC em questão como potencial para um trabalho interdisciplinar a ser realizado em contexto escolar, uma vez que apresenta fronteiras e temas transversais que dialogam com os conteúdos de Ciências. Porém o foco da análise consistiu em identificar os modos de diálogo para a temática Educação Ambiental e assim, realizamos uma análise mais qualificada 
acerca desse ponto do mapeamento. Mas ressaltamos que as demais indicações são importantes e merecem ser investigadas.

\section{Um diálogo com o tema transversal Educação Ambiental: aproximações encontradas}

O tema transversal Educação Ambiental emerge com força neste capítulo pois o autor retrata a situação vivenciada em Chicago nos anos de 1850, que por ser uma cidade em terreno plano não tinha um devido escoamento de esgoto e, quando chovia a cidade inundava na lama de um lodo verde e preto. $\mathrm{O}$ autor $(2015$, p. 111) destaca que "o primeiro sistema de remoção sanitária constava de porcos soltos nas ruas, devorando o lixo que os seres humanos deixavam para trás”. Mas, com o aumento da população, os bueiros passaram a transbordar de sujeira que até os porcos torciam o nariz. Johnson (2015) chama atenção para o seguinte,

o crescimento e a vitalidade das cidades sempre dependeram de nossa capacidade de gerenciar o fluxo dos resíduos humanos que se intensificam quando as pessoas se aglomeram. Desde os primórdios dos assentamentos humanos, descobrir onde colocar os excrementos tem sido tão importante quanto descobrir como construir abrigos, praças ou mercados (JOHNSON, 2015, p. 111).

A leitura dessas questões em sala de aula pode promover um diálogo sobre a necessidade da preocupação com a expansão, com o território, com os cuidados a serem realizados junto ao meio ambiente. O meio ambiente, segundo Reigota (2014) pode ser caracterizado como

um lugar determinado e/ou percebido onde estão em relação dinâmica e em constante interação os aspectos naturais e sociais. Essas relações acarretam processos de criação cultural e tecnológica e processos históricos e políticos de transformações da natureza e da sociedade (REIGOTA, 2014, p.36).

Ao considerar tal afirmativa e, a descrição do contexto social apresentado na obra, é possível apontar para a falta de preocupação com a relação homem-ambiente naquela época, devido à ausência de conhecimentos sócio científicos. Considerando aspectos da atualidade ainda é possível identificar problemas semelhantes, apesar dos avanços tecnológicos, de modo especial, esses problemas se agravam em grandes cidades brasileiras. E ainda, pode-se dialogar acerca de outros problemas que a atual expansão dos centros urbanos causa, como alagamentos, poluição e com isso, chamar os estudantes para um posicionamento e um comportamento a ser desenvolvido. 
Acreditamos que a qualificação do conhecimento acerca da Educação Ambiental possa contribuir para que a relação homem- ambiente possa ser benéfica para ambos. Para Reigota (2014),

a educação ambiental deve procurar favorecer e estimular possibilidades de se estabelecer coletivamente uma "nova aliança" (entre os seres humanos e a natureza e entre nós mesmos) que possibilite a todas as espécies biológicas (inclusive a humana) a sua convivência e sobrevivência com dignidade (REIGOTA, 2014, p. 14).

Seguindo com as considerações de Johnson (2015) sobre o aumento extraordinário da população em centros urbanos e, o consequente aumento de dejetos nas ruas, o autor (2015, p. 112) destaca que toda essa imundície não foi apenas ofensiva para os sentidos, mas "eram mortais. Epidemias de cólera 4 e disenteria irrompiam regularmente [...] e, que as autoridades da época não entendiam bem a conexão entre os resíduos e a doença". Com isso, ressaltamos a necessidade dos conhecimentos da Ciência, que precisam ser aliados nesse diálogo e possibilitar uma conscientização para a população da importância e da necessidade de se discutir e compreender os impactos causados por ações do homem frente ao meio ambiente. Ainda, num contexto escolar é possível trazer aspectos da história da ciência, da evolução de teorias acerca da saúde e/ou doença.

Johnson (2015, p. 112) indica que mesmo sem o conhecimento da bacteriologia, algumas autoridades indicavam uma possível relação entre a limpeza da cidade e o combate a doenças. Em 1855, o engenheiro Ellis Chesbrough foi contratado para tentar solucionar o problema do esgoto. Tendo em vista o problema do terreno plano e não poroso de Chicago, "a criação de um patamar artificial e a construção de esgotos no subsolo foram consideradas saídas muito caras”, isso em função da escassez de equipamentos do séc. XIX.

Portanto, a solução mais barata e, possível para a época, foi suspender os prédios e as casas e fazer a tubulação passar por baixo. Para isso ser possível "tubulações de esgoto foram inseridas sob os edificios, com as galerias principais passando por debaixo das ruas que foram depois recobertas por um aterro retirado do Rio Chicago, suspendendo toda a cidade quase 3 metros em média” (JOHNSON, 2015, p. 113). E, "o resultado foi o primeiro sistema de esgoto aplicável a qualquer cidade

4 No livro O mapa fantasma (JOHNSON, 2008) o autor retrata a epidemia do Cólera em Londres na década de 1854 apresentando discursos/explicações de diferentes naturezas e que estavam muito enraizados em aspectos históricos, religiosos e supersticiosos. 
americana" (JOHNSON, 2015, p. 115). O autor destaca sobre a importância de tal feito indicando que

de todas as conquistas, mais do que os trens de metrô e os cabos de internet de alta velocidade, o mais essencial e mais facilmente esquecido é o pequeno milagre que os sistemas de esgoto ajudaram a tornar possível: desfrutar de um copo de água potável diretamente da torneira (JOHNSON, 2015, p. 116).

Tal fato apresentado, pode ser objeto de investigação por parte dos estudantes quanto às atuais condições e/ou contaminações da água. Como o caso de nascentes poluídas e ainda, buscar dialogar acerca das atuais doenças causadas pela contaminação da água, num movimento de fazer uso do TDC para estimular o posicionamento do estudante, possibilitando a "compreensão de que os estudantes podem transformar a realidade em que vivem com consciência e conhecimento, de maneira crítica” (COSTA; LORENZETTI, 2020, p. 13).

Na continuidade da análise nos chamou a atenção o aspecto de erro apresentado, pois o sistema de esgoto construído por Chesbrough apresentou um erro gravíssimo, devido ao fato de que o engenheiro

concebeu uma estratégia brilhante para afastar os resíduos das ruas, das latrinas e das adegas da vida cotidiana, mas todos os tubos de esgoto escoavam para o rio Chicago, que deságua no lago Michigan, a principal fonte de água potável da cidade (JOHNSON, 2015, p. 116).

Sendo assim, todos os dejetos de uma forma ou outra continuaram a impactar a vida e a saúde dos cidadãos daquela cidade. Segundo Johnson (2015, p. 116) “os verdadeiros assassinos da cidade vitoriana eram as doenças geradas pela água contaminada”. A experiência de Chicago, foi replicada em todo o mundo: esgotos removiam dejetos humanos dos porões e quintais das pessoas, mas, na maioria das vezes, simplesmente eram jogados nas fontes de suprimento de água potável, pelas chuvas torrenciais. Com isso, Johnson (2015, p. 117) ressalta que fazer projetos para galerias de esgoto e tubulações de água na escala da cidade não era por si só suficiente para a tarefa de manter as grandes cidades limpas e saudáveis. Mas era necessário entender o que estava acontecendo na escala de micro organismos. Precisava-se de uma teoria que ligasse os germes à doenças para assim, impedir que os germes prejudicassem a saúde das pessoas. O autor (2015, p. 118-119) ressalta que, lavar as mãos e tomar banho eram atitudes totalmente ignoradas no século XIX, 
tais atitudes foram culturalmente inseridas na nossa sociedade e, "no mundo de hoje vemos a higiene de uma forma radicalmente diferente” (JOHNSON, 2015, p. 119).

Nesse momento, o autor traz uma contextualização acerca da inserção dos cuidados com a higiene pessoal, os quais

foram descobertos e promovidos principalmente por meio dos veículos de reforma social e de boca a boca [..] os arraigados defensores dos banhos foram apoiados pela convergência de vários avanços científicos e tecnológicos importantes. Progressos na infraestrutura pública possibilitaram que mais pessoas tivessem água encanada nas casas para encher as banheiras; a água era mais limpa do que décadas antes e, o mais importante, a teoria dos germes deixou de ser uma ideia marginal para se tornar consenso científico (JOHNSON, 2015, p. 120).

Para tanto, alguns fatores sócio científicos foram muito determinantes, como o trabalho do detetive epidemiológico John Snow que mapeou as mortes causadas pela epidemia de cólera em Londres, mostrando que as mortes eram causadas pela água contaminada e indicando que deveria haver algum microrganismo (que ele chamava de animálculos) na água responsável pela doença ${ }^{5}$. Importante destacar que esse trabalho foi desenvolvido anteriormente à criação do microscópio, que ocorreu no início dos anos 1870 e, também por este motivo Snow não foi reconhecido imediatamente por tal teoria.

A criação dos microscópios foi outro marco para os avanços para a saúde pública, pois possibilitou ao cientista Robert Koch identificar a bactéria da cólera. Ainda, Koch criou maneiras de medir o teor de bactérias permitiu um novo conjunto de abordagens para enfrentar os desafios da saúde pública (JOHNSON, 2015, p. 122).

$\mathrm{E}$, a partir daí passou a se entender que estudar/ analisar questões relativas à contaminação da água significava caminhar em direção à melhorias na saúde pública. Johnson (2015, p. 123) ao considerar a guerra contra os germes/bactérias destaca que "os microscópios e as mensurações logo abriram uma nova frente na guerra contra os germes. Em vez de combatê-los indiretamente, afastando os resíduos da água potável novos produtos químicos poderiam ser usados para atacar diretamente as bactérias."

Nesse momento entra em cena um médico americano chamado John Leal, que segundo Johnson (2015, p. 123) "tinha um interesse apaixonado por questões mais amplas de saúde pública, em particular aquelas relativas à contaminação da água.” O autor (2015, p. 124) aponta que várias técnicas foram experimentadas por Leal

5 Ver mais em O Mapa Fantasma (JOHNSON, 2008). 
para matar bactérias, porém, foi no venenoso hipoclorito de cálcio que ele encontrou a solução.

O hipoclorito de cálcio, potencialmente letal, mais conhecido como cloro, também chamado naquele tempo de "cloreto de cal". A química já tinha grande circulação como remédio para a saúde pública. Casas e bairros que sofriam um surto de febre tifóide ou cólera eram rotineiramente desinfetados com substâncias químicas, intervenção que não fazia nada para combater as doenças causadas pela água. Mas a ideia de colocar cloro na água ainda não tinha sido pensada (JOHNSON, 2015, p. 124).

A partir de seus estudos com o hipoclorito de cálcio Leal "convenceu-se de que o cloro - na dosagem certa - livraria a água das bactérias de forma mais eficaz que qualquer outro meio, sem qualquer ameaça para os homens que a bebessem" (JOHNSON, 2015, p. 124).

Porém, por causa do cheiro forte do cloro, ninguém se convenceu de que adicionando ele à água não traria nenhum malefício e, assim, Leal não conseguiu o convencimento do poder público para tratar a água dessa forma. Em 1908, Leal conseguiu um emprego em uma companhia de fornecimento de água em Nova Jersey e, foi esse trabalho que possibilitou "uma das intervenções mais bizarras e ousadas da história da saúde pública” (JOHNSON, 2015, p. 124).

Leal aproveitou que a empresa em que trabalhava foi multada por cobrar caro pela distribuição da água potável e mesmo assim não conseguir mantê-la "pura e saudável" e em sigilo quase total, com ajuda somente do engenheiro George Warren Fuller e sem qualquer permissão das autoridades governamentais, Leal construiu e instalou um sistema de cloreto de cal para o reservatório da água. Johnson (2015, p. 125) aponta "aquele foi um risco tremendo dada à oposição popular à filtragem química".

O autor (2015, p. 125) destaca ainda que "essa foi a primeira cloração em massa de abastecimento de água de uma cidade na história", marcando uma técnica, que de forma cada vez mais aprimorada, é eficaz até hoje, mais de 100 anos depois.

Quando o fato foi descoberto e se tornou público, Leal foi acusado de cometer terrorismo, pois até então, considerava-se que ingerir uma substância química, mesmo em pequenas quantidades poderia ser letal para qualquer ser humano. Leal foi levado aos tribunais para se defender e, segundo Johnson (2015, p. 125), durante o interrogatório "ele manteve-se firme na defesa de sua descoberta em saúde pública", o que culminou no final do julgamento em uma vitória quase completa de Leal. 
Toda essa questão da evolução da compreensão ciência/teoria/sociedade contempla visões epistemológicas de como é preciso muitas vezes romper com um paradigma para aceitar o novo. E ainda, destacamos o fato da incompreensibilidade acerca do uso de substâncias químicas, sendo que ainda hoje, muitas vezes a visão que se tem é de que se algo é dito como químico faz mal. Isso também remete para questões culturais que precisam ser dialogadas em sala de aula e que se não compreendidas dificultam a construção do conhecimento científico.

O capítulo analisado ainda possibilita ao professor trazer para a sala de aula aspectos de como evolui o conhecimento científico pois retrata a validação e a inicial recusa a novas teorias. Johnson (2015) aponta que a vitória e absolvição de Leal foram possíveis devido a estudos e pesquisas realizadas com as populações que ingeriram a água tratada. Segundo Johnson (2015)

em poucos anos os números que validaram a ousadia de Leal tornaram-se incontestáveis: comunidades como Jersey City, que tomavam água potável clorada tiveram reduções radicais nas doenças transmitidas pela água, como febre tifóide (JOHNSON, 2015, p. 126)

Apesar de avanços o autor (2015) destaca que, quando olhamos para cidades bem desenvolvidas, a história do último século e meio parece ser de progressos incontestáveis: a água é mais limpa, as taxas de mortalidade são muito mais baixas; as doenças epidêmicas quase inexistem. Mas até hoje há mais de 3 bilhões de pessoas no mundo todo que não tem acesso à água potável e sistemas básicos de saneamento (JOHNSON, 2015, p. 133)

Apontamos que tal problemática já não é mais uma questão só de saúde pública, mas também de políticas públicas, que não atendem às necessidades da população e sobre isso indicamos a importância da inserção do diálogo da Educação Ambiental como de inserção de uma educação política que contemple

a análise das relações políticas, econômicas, sociais e culturais entre a humanidade e a natureza e as relações entre os seres humanos, visando a superação dos mecanismos de controle e de dominação que impedem a participação livre, consciente e democrática de todos (REIGOTA, 2014, p.13).

Ainda para Reigota (2014) a Educação Ambiental como educação política está comprometida com a ampliação da cidadania, da liberdade, da autonomia, e da intervenção direta dos cidadãos e das cidadãs na busca de soluções alternativas que permitam a convivência digna e voltada para o bem comum. (REIGOTA, 2014, p.13). 
Dessa forma consideramos que ao aliar a Divulgação Científica com a Educação Ambiental é possível ampliar as discussões para além apenas de informações isoladas, mas também contextualizar tais informações no sentido de que contribuam para a construção de uma sociedade preocupada e interessada em discutir questões ambientais e sócio científicas com um olhar crítico e científico necessário de ser desenvolvido em contexto escolar.

\section{Considerações finais}

A análise do livro possibilitou a indicação de possibilidades para a utilização deste texto em sala de aula, principalmente no que se refere à questões relacionadas a construção do conhecimento científico e o posicionamento dos estudas frente às temáticas sócio científicas num diálogo com conteúdos mais específicos, em especial os temas transversais, conforme está apresentado no mapeamento que realizamos.

Ainda, com a análise realizada indicamos que a leitura de TDC quando muito bem planejada, organizada pelo professor pode qualificar a inserção de temáticas emergentes no contexto escolar, como as questões de Educação Ambiental e Saúde Pública. O capítulo Higiene, que foi objeto de análise, pode ser problematizado para os alunos considerando o tratamento da água, o correto uso e o descarte de dejetos e com isso, possibilitar uma melhor compreensão de tais fenômenos e da responsabilidade do homem frente ao descarte e cuidado com o meio ambiente.

Ainda, de modo especial, a análise realizada possibilita apontar que o capítulo auxilia na compreensão da construção humana da Ciência ao presentar aspectos sócio históricos frente à questão da contaminação microbiana e a evolução científica e assim, qualificando construção do conhecimento científico.

Os diferentes avanços da Ciência, as compreensões acerca de uma nova teoria sempre tiveram um embate social, são questões controversas e transversais, mas que precisam ser estudadas no contexto escolar a fim de possibilitar a formação de sujeitos mais críticos e participativos. Daí ressaltamos que questões emergentes de Divulgação Científica que fazem parte do cotidiano dos estudantes se tornam significativas ao serem compreendidas à luz dos conhecimentos escolares e vice versa. Por fim, reafirmamos com Maldaner (2014) de que é importante trabalhar textos que relacionem aspectos mais amplos com os conteúdos a ensinar, não apenas textos de livros didáticos, mas outros que potencializem processos interativos de 
discussão, busca de informações e de pesquisas. Com isso, apostamos na inserção de TDC por meio de leituras que possibilitem, que qualifiquem o diálogo acerca de temáticas como Educação Ambiental em contexto escolar.

\title{
Evidence of Approximations between Environmental Education and Scientific Dissemination in the Book How We Got Here
}

\begin{abstract}
This article deals with Scientific Dissemination and Environmental Education as a way to qualify the construction of scientific knowledge and promote the formation of readers with a critical position in the school context. To this end, we performed a qualitative document analysis and mapped one of the chapters of the book on Scientific Dissemination How We Got Here, authored by Steven Johnson whose title is Hygiene. This made it possible to highlight the didactic possibilities for its use in the classroom, with special attention to Environmental Education as a cross-cutting theme. In general, the book discusses the innovations and technological advances that constituted today's society and that made modern life possible. And, the results presented make it possible to see that combining Scientific Dissemination with Environmental Education can be a way of contextualizing socio-scientific issues with a critical and scientific perspective in the school context.
\end{abstract}

Keywords: Scientific Dissemination Texts, Public Health, Science Teaching.

\section{Referências}

BERTOLDO, Raquel Roberta; CUNHA, Márcia Borin da; STRIEDER, Dulce Maria; SILVA, Alex Sander da. In: CUNHA, Márcia Borin da; GORDAN, Marcelo. (Orgs). Divulgação Científica na sala de aula: perspectivas e possibilidades. Ijuí: Ed. Unijuí, 2015, 360p.

BUENO, Wilson da Costa. Comunicação Científica e Divulgação Científica: aproximações e rupturas conceituais. Inf. Inf., Londrina, v. 15, n. esp., pp. 1-12, 2010. Disponível em: http://www. uel.br/revistas/uel/index.php/informacao/article/view/6585. Acesso em: 01/09/2020.

COLPO, Camila. Carolina. Estratégias de leitura de Textos de Divulgação Científica e a constituição docente de uma professora de Química. Revista Insignare Scientia- RIS, v. 2, n. 3, p. 48-55, 2019. Disponível em: https://periodicos.uffs.edu.br/index.php/RIS/article/view/11180. Acesso em: 01/09/2020.

COSTA, Ellen Moreira da; LORENZETTI, Leonir. A promoção da alfabetização científica nos anos finais do ensino fundamental por meio de uma sequência didática sobre crustáceos. Revista Brasileira de Ensino de Ciências e Matemática. RBECM. v. 3, n. 1, p. 11-47, 2020. Disponível em: http://seer.upf.br/index.php/rbecm/article/view/10006. Acesso em: 01/09/2020.

CUNHA, Márcia Borin da. Divulgação Científica: diálogos com o ensino de Ciências. 1 ed. Curitiba: Appris, 2019. 
CUNHA, Márcia Borin da; GIORDAN, Marcelo. A divulgação científica na sala de aula: implicações de um gênero. In: (Orgs). Divulgação Científica na sala de aula: perspectivas e possibilidades. Ijuí: Ed. Unijuí, 2015, 360 p.

FERREIRA, Luciana Nobre de Abreu, QUEIROZ, Salete Linhares. Características discursivas de artigos de divulgação científica relacionados à química. Revista Electrónica de Enseñanza de las Ciencias. Vol. 11, № 1, p. 21-42, 2012. Disponível em: http://reec.uvigo.es/volumenes/ volumen11/REEC_11_1_2_ex543.pdf. Acesso em: 01/09/2020.

FERREIRA, Luciana Nobre de Abreu, QUEIROZ, Salete Linhares. Artigos da revista Ciência Hoje como recurso didático no ensino de química. Química Nova, v. 34, n. 2, p. 354-360, 2011. Disponível em: http://quimicanova.sbq.org.br/detalhe_artigo.asp?id=4513. Acesso em: 01/09/2020.

JOHNSON, Steven. O mapa fantasma: como a luta de dois homens contra a cólera mudou o destino de nossas metrópoles. 1 ed. Rio de Janeiro: Zahar, 2008, 272p.

JOHNSON, Steven. A invenção do ar: uma saga de Ciência, fé, revolução e o nascimento dos Estados Unidos. Rio de Janeiro: Zahar, 2009, 218 p.

JOHNSON, Steven. Como chegamos até aqui: a história das inovações que fizeram a vida moderna possível. 1 ed. Rio de Janeiro: Zahar, 2015, 235 p.

LÜDKE, Menga; ANDRÉ, Marli. A. Pesquisa em educação: abordagens qualitativas. São Paulo: EPU, 2001.

MALDANER, Otavio. Aloisio. Formação de Professores para um contexto de referência conhecida. In: NERY, Belmayr Knopki; MALDANER, Otavio Aloisio (org.). Formação de professores: compreensões em novos programas e ações. Ijuí, ed.Unijuí, 2014, p. 15-42.

REIGOTA, Marcos. O que é Educação Ambiental. São Paulo: Brasiliense, 2014. 107p.

ZAMBONI, Lilian Márcia Simões. Cientistas, jornalistas e a divulgação científica: subjetividade e heterogeneidade no discurso da divulgação científica. Campinas: FAPESP/Editora Autores Associados, 2001. 